\title{
Contributors
}

\section{CONSULTING EDITORS}

RANJAN K. THAKUR, MD, MPH, MBA, FHRS Professor of Medicine and Director, Arrhythmia Service, Thoracic and Cardiovascular Institute, Sparrow Health System, Michigan State University, Lansing, Michigan

\section{ANDREA NATALE, MD, FACC, FHRS} Executive Medical Director, Texas Cardiac Arrhythmia Institute, St. David's Medical Center, Austin, Texas; Consulting Professor, Division of Cardiology, Stanford University, Palo Alto, California; Adjunct Professor of Medicine, Heart and Vascular Center, Case Western Reserve University, Cleveland, Ohio; Director, Interventional Electrophysiology, Scripps Clinic, San Diego, California; Senior Clinical Director, EP Services, California Pacific Medical Center, San Francisco, California

\section{EDITOR}

\section{HUGUES ABRIEL, MD, PhD}

Professor of Pathophysiology; Director, Department of Clinical Research, Ion Channel and Channelopathies Research Group, University of Bern, Bern, Switzerland

\section{AUTHORS}

\section{HUGUES ABRIEL, MD, PhD}

Professor of Pathophysiology; Director, Department of Clinical Research, Ion Channel and Channelopathies Research Group, University of Bern, Bern, Switzerland

\section{RONG BAI, MD}

Cardiologist, Department of Cardiology, Beijing An Zhen Hospital, Capital Medical University, Beijing, China

\section{YANGYANG BAO, BS}

Department of Pharmacology, University of Michigan Medical School, Ann Arbor, Michigan

\section{JULIEN BARC, PhD}

Department of Experimental Cardiology, Academic Medical Center, Amsterdam, The Netherlands

\section{WOODROW BENSON, MD, PhD}

Department of Cardiology, Children's Hospital of Wisconsin; Professor of Pediatrics and Director, Congenital and Pediatric Cardiac Research, Medical College of Wisconsin, Milwaukee, Wisconsin

\section{CONNIE R. BEZZINA, PhD}

Department of Experimental Cardiology, Academic Medical Center, Amsterdam, The Netherlands

\section{LIA CROTTI, MD, PhD}

Center for Cardiac Arrhythmias of Genetic Origin and Laboratory of Cardiovascular Genetics, IRCCS Istituto Auxologico Italiano, Milan, Italy; Department of Molecular Medicine, University of Pavia, Pavia, Italy; Helmholtz Zentrum München, Institute of Human Genetics, Neuherberg, Germany 


\section{DAWOOD DARBAR, MD}

Director, Vanderbilt Arrhythmia Service and Cardiac EP Fellowship Program; Associate Professor of Medicine, Division of Cardiovascular Medicine, Vanderbilt University, Nashville, Tennessee

\section{SERGEI DZEMESHKEVICH, MD, PhD}

Professor, Director, Head of Heart Surgery Department, Petrovsky Russian Research Centre of Surgery, Moscow, Russia

\section{ALICE GHIDONI, PhD}

Laboratory of Cardiovascular Genetics, IRCCS Istituto Auxologico Italiano, Milan, Italy; Department of Molecular Medicine, University of Pavia, Pavia, Italy

\section{JEAN-BAPTISTE GOURRAUD, MD}

Reference Centre for Hereditary Arrhythmic

Diseases, Cardiologic Department and INSERM U1087, l'institut du thorax, CHU de Nantes, Nantes, France

\section{ROBERTO INSOLIA, PhD}

Department of Molecular Medicine, University of Pavia, Pavia, Italy

\section{LORI L. ISOM, PhD}

Professor of Pharmacology and Professor of Molecular and Integrative Physiology, Department of Pharmacology, University of Michigan Medical School, Ann Arbor, Michigan

\section{ANDRE G. KLEBER, MD}

Visiting Professor, Department of Pathology, Beth Israel Deaconess Medical Center, Harvard Medical School, Boston, Massachusetts

\section{JOSHUA R. KOVACH, MD}

Assistant Professor, Pediatrics, Cardiology, Children's Hospital of Wisconsin, Medical College of Wisconsin, Milwaukee, Wisconsin

\section{JOHN W. KYLE, PhD}

Senior Scientist, Division of Cardiovascular Medicine, Department of Medicine, University of Wisconsin, Madison, Wisconsin

\section{FLORENCE KYNDT, PharmD, PhD}

Reference Centre for Hereditary Arrhythmic Diseases and INSERM U1087, l'institut du thorax, $\mathrm{CHU}$ de Nantes, Nantes, France

\section{HERVÉ LE MAREC, MD, PhD}

Reference Centre for Hereditary Arrhythmic Diseases, Cardiologic Department and INSERM U1087, l'institut du thorax, CHU de Nantes, Nantes, France

\section{NIAN LIU, MD}

Clinical Cardiologist and Research Scientist, Department of Cardiology, Beijing An Zhen Hospital, Capital Medical University, Beijing, China

\section{JONATHAN C. MAKIELSKI, MD}

Professor of Medicine, Division of Cardiovascular Medicine, Department of Medicine, University of Wisconsin, Madison, Wisconsin

\section{ARGELIA MEDEIROS-DOMINGO, MD, PhD} Department of Cardiac Electrophysiology, University Hospital of Bern, Bern, Switzerland

\section{YUKA MIZUSAWA, MD}

Department of Cardiology, Heart Center, Academic Medical Center, Amsterdam, The Netherlands

\section{CARLO NAPOLITANO, MD, PhD}

Associate Professor, Molecular Cardiology, IRCCS, Fondazione Salvatore Maugeri, Pavia, Italy; Cardiovascular Genetics, Leon Charney Division of Cardiology, New York University, New York, New York

\section{SEAN O'ROURKE, MD ${ }^{\dagger}$}

New York University, New York, New York

\section{PIETER G. POSTEMA, MD, PhD}

Department of Cardiology, Heart Center, Academic Medical Center, Amsterdam, The Netherlands

\section{SILVIA G. PRIORI, MD, PhD}

Professor of Medicine, Molecular Cardiology, IRCCS, Fondazione Salvatore Maugeri; Department of Molecular Medicine, University of Pavia, Pavia, Italy

\section{VINCENT PROBST, MD, PhD}

Professor of Cardiology, Reference Centre for Hereditary Arrhythmic Diseases, Cardiologic Department and INSERM U1087, I'institut du thorax, $\mathrm{CHU}$ de Nantes, Nantes, France 
RICHARD REDON, PhD

Reference Centre for Hereditary Arrhythmic Diseases and INSERM U1087, l'institut du thorax, $\mathrm{CHU}$ de Nantes, Nantes, France

CAROL ANN REMME, MD, PhD

Department of Experimental Cardiology, Academic Medical Center, University of Amsterdam, Amsterdam, The Netherlands

\section{DAN M. RODEN, MD}

Departments of Medicine and Pharmacology, Vanderbilt University School of Medicine, Nashville, Tennessee

\section{YANFEI RUAN, MD}

Clinical Cardiologist, Department of Cardiology, Beijing An Zhen Hospital, Capital Medical University, Beijing, China

ELEONORA SAVIO-GALIMBERTI, MD, PhD Research Fellow in Cardiovascular Medicine, Division of Cardiovascular Medicine, Vanderbilt University, Nashville, Tennessee

\section{JEAN-JACQUES SCHOTT, PhD}

Reference Centre for Hereditary Arrhythmic Diseases and INSERM U1087, l'institut du thorax, CHU de Nantes, Nantes, France

\section{PETER J. SCHWARTZ, MD}

Center for Cardiac Arrhythmias of Genetic Origin and Laboratory of Cardiovascular Genetics, IRCCS Istituto Auxologico Italiano, Milan, Italy

HANNO L. TAN, MD, PhD

Department of Cardiology, Heart Center, Academic Medical Center, Amsterdam,

The Netherlands

\section{CARMEN R. VALDIVIA, MD}

Center for Arrhythmia Research, University of Michigan, Ann Arbor, Michigan

\section{RAYMOND L. WOOSLEY, MD, PhD}

Arizona Center for Education and Research on Therapeutics (AZCERT), Oro Valley, Arizona; University of Arizona, College of MedicinePhoenix, Phoenix, Arizona

ELENA ZAKLYAZMINSKAYA, MD, PhD Professor, Head of Medical Genetics Laboratory, Petrovsky Russian Research Centre of Surgery, Moscow, Russia 